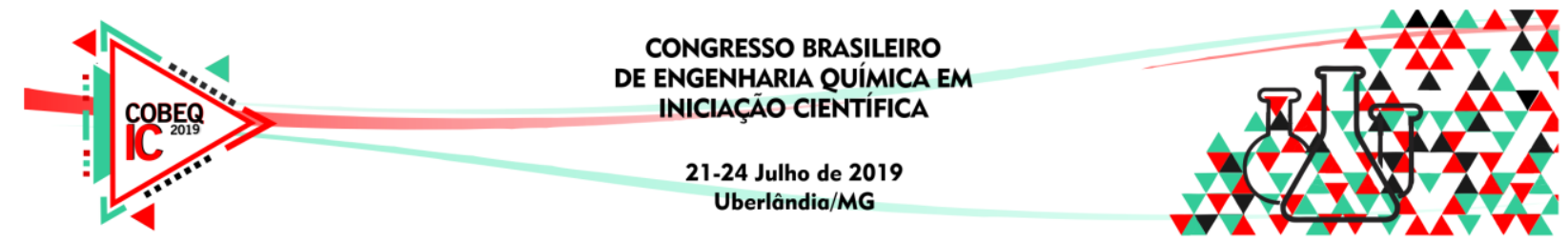

\title{
APLICAÇÃO DE FOTOPEROXIDAÇÃO, FOTO-OXIDAÇÃO E NANOFILTRAÇÃO PARA TRATAMENTO DE ÁGUAS RESIDUÁRIAS TÊXTEIS
}

\author{
A. P. B. ARAÚJO' ${ }^{1}$, B. T. OLIVEIRA ${ }^{1}$, G. C. MOREIRA ${ }^{1}$, B. C. RICCI $^{1}$ e L. H. ANDRADE ${ }^{1}$ \\ ${ }^{1}$ Pontifícia Universidade Católica de Minas Gerais, Departamento de Engenharia Química \\ E-mail para contato: alessandra.araujoo20@gmail.com
}

\begin{abstract}
RESUMO - O tratamento do efluente têxtil representa um desafio às indústrias devido a sua complexidade e alta variabilidade. Ademais, levando em consideração o atual período de escassez mundial de água e a ineficiência dos sistemas convencionais de tratamento utilizados, torna-se necessário o estudo de novas tecnologias. Desse modo, o presente trabalho teve como objetivo avaliar a associação da fotoperoxidação, foto-oxidação UV e nanofiltração (NF), utilizando ultrafiltração (UF) como pré-tratamento. A resistência da incrustação da membrana, a reversibilidade dessa incrustação e o fluxo de permeado foram avaliados, assim como a taxa de recuperação para a melhor rota de tratamento. $\mathrm{O}$ planejamento fatorial foi usado como ferramenta para definir as melhores condições de pressão de filtração e dosagem de peróxido de hidrogênio $\left(\mathrm{H}_{2} \mathrm{O}_{2}\right)$. Os resultados mostraram elevadas remoções de condutividade para todas as rotas avaliadas, entretanto, a rota composta apenas pela NF apresentou melhor resultado, em relação ao fluxo de permeado e a remoção da incrustação. Desse modo, essa foi determinada como a melhor rota, cuja taxa de recuperação máxima, a 8,5 bar, foi de $40 \%$. Ademais, o efluente final se mostrou apto a ser reutilizado na indústria nas etapas de lavagem, tingimento, branqueamento, bem como em sanitários, na limpeza de galpões e equipamentos.
\end{abstract}

\section{INTRODUÇÃO}

A indústria têxtil é um dos setores que mais contribuem para a economia dos países desenvolvidos. Porém, geram um grande volume de efluente durante os processos de fabricação de seus produtos, sendo um dos mais poluentes para os corpos hídricos e para os solos (KIM et al., 2006). Aproximadamente 125 a $150 \mathrm{~m}^{3}$ de água são utilizados para 1 tonelada de produto têxtil (KORBAHTI e TANYOLAÇ, 2008).

A composição do efluente têxtil é complexa devido a variados produtos químicos e reagentes auxiliares utilizados no processo produtivo tais como corantes, metais pesados, pigmentos, detergentes, sais, compostos de enxofre, óleos e graxas. Esses contaminantes podem causar sérios danos à saúde, uma vez que são tóxicos, mutagênicos e cancerígenos (BAFANA et al., 2009). Segundo Kunz et al. (2002), os métodos de tratamento convencionalmente aplicados na indústria têxtil se baseiam em processos físico-químicos e biológicos, como a precipitação/coagulação e os sistemas de lodos ativados. Tais tratamentos propiciam uma elevada remoção dos corantes, entretanto, concomitantemente, ocorre a produção de lodo, bem como a adsorção de corantes a esse lodo, gerando, assim, um novo resíduo. Ademais, de acordo com Firmino et al. (2010), os corantes e pigmentos aplicados no processo têxtil são projetados para resistir à biodegradação, o que permite que esses 


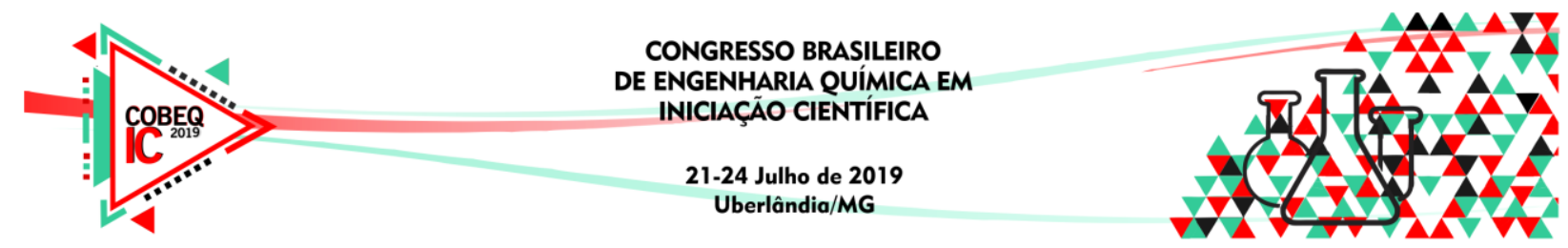

permaneçam no meio ambiente por um longo período de tempo, mesmo após a passagem pelas Estações de Tratamento de Efluentes (ETE).

Nesse sentido, devido à baixa eficiência dos tratamentos convencionais para os efluentes têxteis, surgem novas alternativas. Dentre elas, destacam-se os processos oxidativos avançados (POA) e os processos de separação por membranas. Os POAs são técnicas de degradação oxidativa nas quais ocorre a geração in situ de espécies oriundas do oxigênio altamente oxidantes, capazes de promover a mineralização da matéria-orgânica ou degradá-la parcialmente. É uma técnica já consolidada e efetiva no tratamento de água e efluentes para remoção de compostos orgânicos que apresentam alta estabilidade química e/ou recalcitrantes (MARCELINO, 2014).

Por outro lado, os processos de separação por membranas referem-se a um processo físico em que, devido à ação de uma força motriz, promove a separação de determinados compostos em suspensão ou em solução. Entre os tipos existentes, a nanofiltração vem se destacando no tratamento de efluente têxtil, visto que esse processo possibilita a remoção de compostos com baixa massa molar, além de íons bi e multivalentes, com peso molar de $700 \mathrm{a}$ $1000 \mathrm{Da}$ (CHOLLOM et al., 2015).

Conforme KUNZ et al. (2002), a combinação de métodos para o tratamento dos efluentes de indústria têxtil é o ideal, uma vez que os corantes presentes normalmente se mostram resistentes à degradação. Desse modo, o objetivo deste trabalho foi avaliar a aplicação de processos químicos (fotoperoxidação ou foto-oxidação) e físicos (ultrafiltração e nanofiltração) como pós-tratamento de efluente têxtil previamente tratado por processos convencionais.

\section{METODOLOGIA}

\subsection{Amostras}

O efluente foi coletado em uma indústria têxtil localizada em Minas Gerais. Este é submetido a um tratamento prévio, sendo a sua coleta feita na saída do decantador. A fim de conhecer a amostra a ser trabalhada, o efluente foi caracterizado a partir de parâmetros físicoquímicos, de acordo com o Standard Methods for Examination of Water and Wastewater (APHA, 1999).

\subsection{Pré-tratamento do efluente}

O efluente foi pré-tratado por ultrafiltração (UF), a fim de evitar danos à nanofiltração. $\mathrm{O}$ módulo de UF utilizado foi o GE-Zenon ZW-1, com área de filtração de $0,047 \mathrm{~m}^{2}$ e diâmetro de poro nominal de $0,04 \mu \mathrm{m}$. Posteriormente, o permeado da UF foi caracterizado por meio dos parâmetros $\mathrm{pH}$, condutividade e turbidez.

\subsection{Ensaios de fotoperoxidação}

O efluente ultrafiltrado foi submetido à fotoperoxidação, a qual foi realizada com a lâmpada UV-611/HOPAR, potência de 24 a $36 \mathrm{~W}$, por um tempo reacional de 2 horas, utilizando 2 litros de efluente e com a temperatura controlada em torno de $25{ }^{\circ} \mathrm{C}$ com o chiller. Após o processo de fotoperoxidação, o efluente foi caracterizado conforme os parâmetros definidos pós-ultrafiltração. 


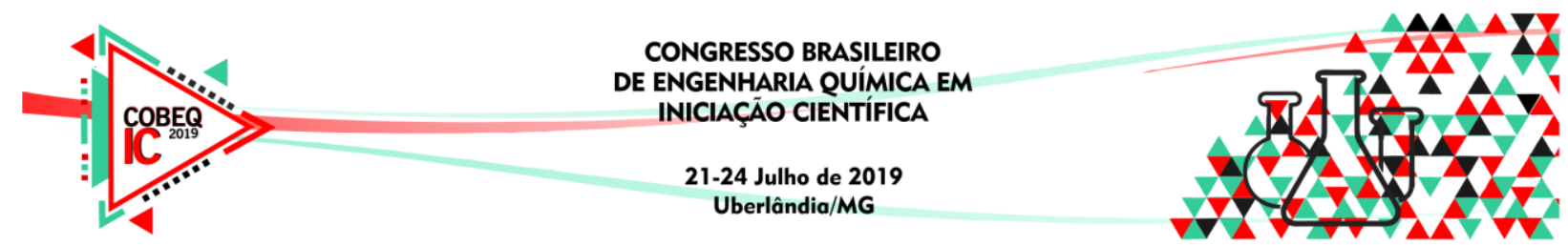

\subsection{Ensaios de nanofiltração}

A etapa de nanofiltração foi realizada com o auxílio de uma unidade experimental constituída por um módulo de aço inox, no qual a membrana foi inserida, como demonstrado por Ricci (2015). A membrana utilizada foi a NF90 (DowFilmtec), com área de filtração é de $0,0064 \mathrm{~m}^{2}$. Antes da filtração, todos os recortes de membranas foram reumidificados em solução de água e álcool $50 \%$ v/v e, posteriormente, compactadas com água destilada à pressão de 10 bar, até estabilização do fluxo de permeado. Em seguida, mediu-se a sua permeabilidade hidráulica. A nanofiltração foi realizada à pressão constante com recirculação total do permeado e do concentrado para o tanque de alimentação. Durante a filtração, a temperatura da alimentação e o fluxo do permeado foram controlados regularmente. Ao final de cada teste, as amostras de efluente tratado foram caracterizados segundo parâmetros de $\mathrm{pH}$, condutividade e turbidez.

\subsection{Planejamento fatorial}

Para verificar a influência da conjugação da fotoperoxidação com a nanofiltração, um planejamento fatorial foi proposto, sendo avaliados dois fatores, a dosagem de $\mathrm{H}_{2} \mathrm{O}_{2}$ na alimentação da NF, que consistiu no permeado da UF, e a pressão de operação da nanofiltração, com três repetições do ponto central e assumindo $95 \%$ de confiança. Os valores de dosagem testados foram de 1:0, 1:0,15 e 1:0,3 mgСот $/ \mathrm{mg}_{\mathrm{H} 2 \mathrm{O} 2}$, e as pressões de operação da NF foram de 4, 7 e 10 bar, sendo o tempo de filtração equivalente a 60 minutos. A variável resposta foi a eficiência de remoção de condutividade. A partir dos testes, foi possível determinar o ponto de máxima eficiência de remoção por meio do software Statistica 10.

\subsection{Rotas avaliadas}

O ponto ótimo determinado estatisticamente foi avaliado experimentalmente. Para tanto, três rotas foram propostas utilizando os dados obtidos pelo modelo, sendo elas o uso do POA seguido de NF, NF sem processo oxidativo precedente e foto-oxidação UV, ou seja, sem o uso do $\mathrm{H}_{2} \mathrm{O}_{2}$, seguida de NF. Em relação aos experimentos com NF, o tempo de filtração estabelecido foi de 120 minutos. Para mais, ao final dos testes, as membranas utilizadas foram submetidas à limpeza física, a qual foi feita pela recirculação da água por 30 minutos na unidade de nanofiltração, com a vazão de $2,4 \mathrm{~L} / \mathrm{min}$, na ausência de pressão. A partir da limpeza física da membrana foi possível calcular as resistências às incrustações, de acordo com Ricci (2015).

\subsection{Taxa de recuperação}

Por fim, após a avaliação da melhor rota proposta, foi realizado o teste de taxa de recuperação, que consistiu no mesmo processo inicial de tratamento da membrana, para posterior realização da coleta de permeado, em que foi utilizada a pressão de operação do ponto ótimo. O permeado foi coletado ao início da filtração e em frações de 5\%, com intervalos de 30 minutos para estabilização do fluxo. Após o teste de taxa de recuperação, as frações coletadas foram caracterizadas através de parâmetros como $\mathrm{pH}$ e condutividade, de modo a avaliar a qualidade do permeado obtido e, assim, verificar se a taxa de recuperação máxima alcançada foi a ideal. 


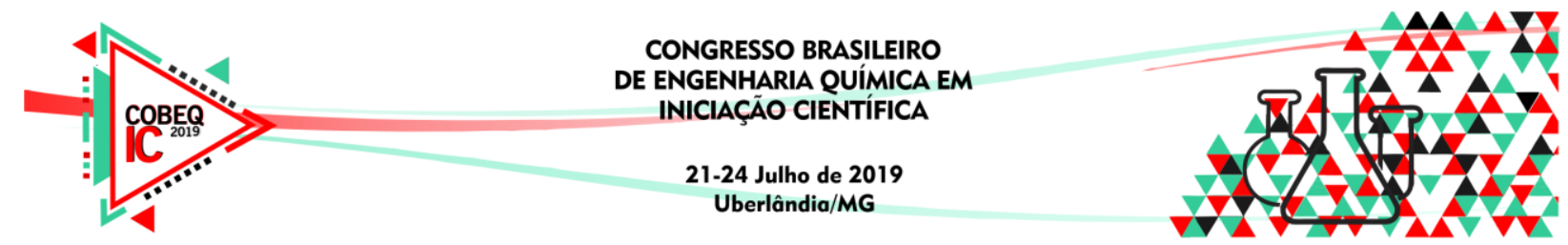

\section{RESULTADOS E DISCUSSÕES}

O planejamento fatorial desenvolvido permitiu a obtenção de um ponto ótimo, de máxima eficiência de remoção para condutividade, sendo o valor de dosagem requerido equivalente a 1:0,24 mg $\mathrm{COT} / \mathrm{mg}_{\mathrm{H} 2 \mathrm{O} 2}$ e pressão de 8,5 bar. A Figura 1 evidencia a superfície de resposta obtida para a avaliação desses parâmetros.

Figura 1 - Superfície de resposta em relação à remoção de condutividade.

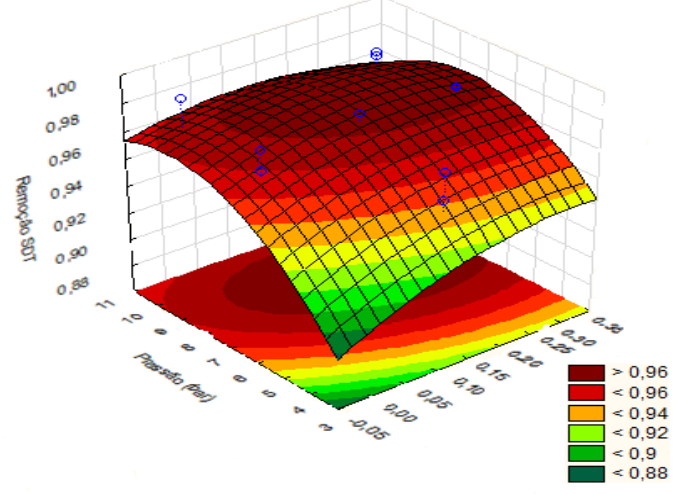

A replicação da condição ótima nas rotas com e sem o uso do $\mathrm{H}_{2} \mathrm{O}_{2}$, bem como com o uso da nanofiltração permitiu analisar a influência de cada processo no fluxo de permeado e na condutividade, como mostrado na Tabela 1 e na Figura 2.

Tabela 1 - Caracterização das amostras de acordo com suas condutividades

\begin{tabular}{cccccc}
\hline \multicolumn{1}{c}{ Amostra } & $\begin{array}{c}\text { Efluente } \\
\text { bruto }\end{array}$ & Efluente UF & $\begin{array}{c}\text { Permeado } \\
(\mathrm{UF}+\mathrm{UV}+\mathrm{NF})\end{array}$ & $\begin{array}{c}\text { Permeado } \\
(\mathrm{UF}+\mathrm{POA}+\mathrm{NF})\end{array}$ & $\begin{array}{c}\text { Permeado } \\
(\mathrm{UF}+\mathrm{NF})\end{array}$ \\
\hline Condutividade $(\mu \mathrm{S} / \mathrm{cm})$ & 6420 & 6130 & 115,2 & 140,8 & 157,3 \\
\hline
\end{tabular}

A Tabela 1 apresenta as elevadas remoções de condutividade alcançadas pela aplicação de todos os tratamentos, evidenciando o potencial dos mesmos para a obtenção de permeados de qualidade, visto que uma menor condutividade está associada a uma menor concentração de sólidos dissolvidos. Apesar da melhor qualidade do permeado obtido pela associação entre o POA e a NF, por meio da análise da Figura 2 é possível perceber a redução do fluxo quando o efluente foi submetido à radiação UV ou à fotoperoxidação, indicando a presença de uma maior incrustação. Esse efeito ocorre em razão do fenômeno de polarização por concentração, devido à acumulação de solutos na superfície da membrana. Essas incrustações formadas podem ser avaliadas pelas suas respectivas resistências, de acordo com a Tabela 2.

Figura 2 - Avaliação do fluxo de permeado em função do tempo para cada rota aplicada na dosagem de 1:0,24 mg $\mathrm{COT} / \mathrm{mg}_{\mathrm{H} 2 \mathrm{O} 2}$ e pressão de 8,5 bar.

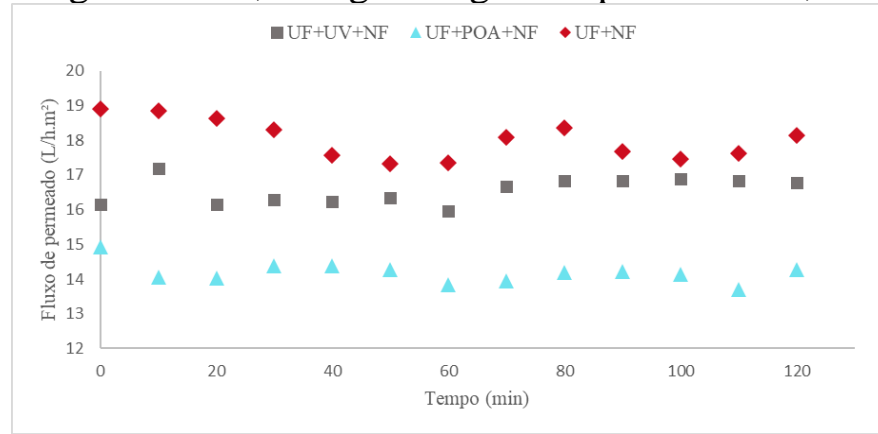




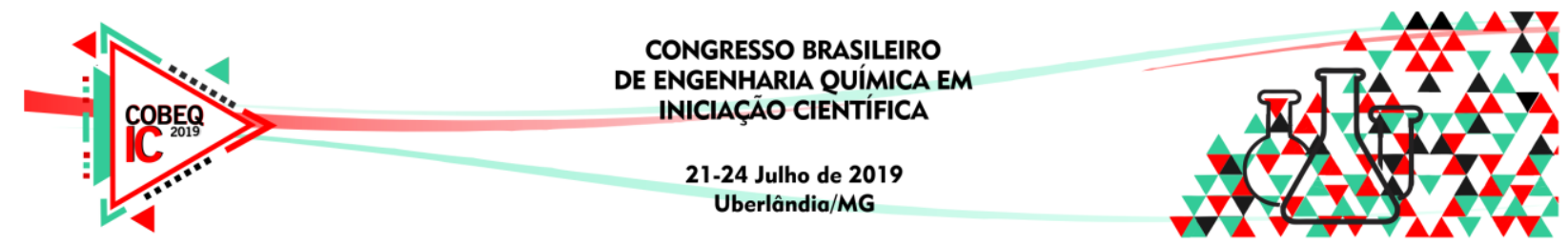

Ao analisar as três rotas, a aplicação do pré-tratamento por UF seguido da NF se mostrou mais eficiente, tendo em vista a formação de uma menor incrustação total, a qual é composta majoritariamente pela incrustação reversível, não necessitanto da aplicação de processos químicos para limpeza da membrana. No caso do uso do UV e do $\mathrm{UV} / \mathrm{H}_{2} \mathrm{O}_{2}$, a redução do fluxo pode ser decorrência do aumento da pressão osmótica da alimentação, uma vez que não foi verificada a mineralização total dos compostos presentes no efluente tratado. Esse efeito ocorre pelo fato da aplicação desses processos levar à quebra de compostos orgânicos da matriz do efluente, entretando levando à formação de um maior número de partículas, sendo a pressão osmótica uma função direta desse número de partículas.

Tabela 2 - Resistências associadas à membrana de NF

\begin{tabular}{cccc} 
& UF+UV+NF & UF+NF & UF+POA+NF \\
\hline Resistência $\left(\mathbf{m}^{-\mathbf{1}}\right)$ & Valor $\left(\mathbf{x 1 0}^{\mathbf{1 4}}\right)$ & Valor $\left(\mathbf{x 1 0}^{\mathbf{1 4}}\right)$ & Valor $\left(\mathbf{x 1 0}^{\mathbf{1 4}}\right)$ \\
\hline Membrana & 1,17 & 1,26 & 1,20 \\
Incrustação total & 0,51 & 0,33 & 0,81 \\
Incrustação reversível & 0,34 & 0,19 & 0,69 \\
Incrustação irreversível & 0,17 & 0,15 & 0,12 \\
\hline
\end{tabular}

A análise da taxa de recuperação foi realizada para a rota UF+NF, em concordância com o resultado obtido anteriormente. A Figura 3 ilustra o fluxo de permeado no decorrer da sua taxa de recuperação, assim como evidencia a resposta da condutividade ao experimento.

Figura 3 - Fluxo de permeado e condutividade em função da taxa de recuperação.

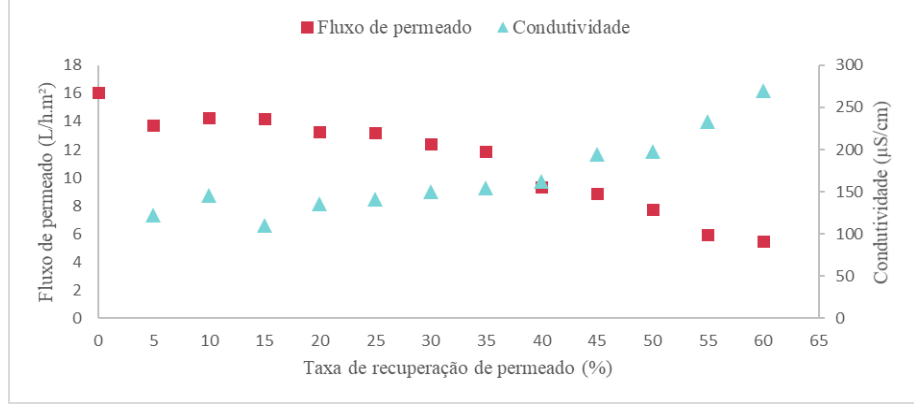

Por meio da análise gráfica, a taxa máxima recomendada para operação é de $40 \%$, tendo em vista uma maior queda do fluxo a partir dessa conversão, algo que pode estar relacionado à concentração por polarização, processos de adsorção na superfície da membrana ou pela alta concentração de sais. Ademais, o aumento da condutividade no decorrer do experimento também é verificado, sendo mais acentuado após essa mesma taxa. Esse aumento se deve ao fato de que à medida que a taxa de recuperação se desenvolve ocorre o aumento da concentração de sais e, por consequência, aumenta a força-motriz para a transferência de massa, fazendo com que comece a haver a passagem de sais para o permeado.

\section{CONCLUSÃO}

Perante o exposto, os processos se demonstraram como alternativas promissoras para o tratamento de águas residuais têxteis, uma vez que todas as rotas avaliadas apresentaram remoção de condutividade superior a $97 \%$. Entretanto, concomitantemente, a fotoperoxidação e a fotooxidação obtiveram uma maior incrustação associada, provocando menores fluxos de permeados. Desse modo, como o impacto do fluxo de permeado também deve ser avaliado, a aplicação apenas da NF é aconselhável, pois apresentou um menor decaimento do fluxo. Outrossim, ao avaliar a taxa de recuperação de permeado aplicada ao processo de NF foi possível atingir uma 


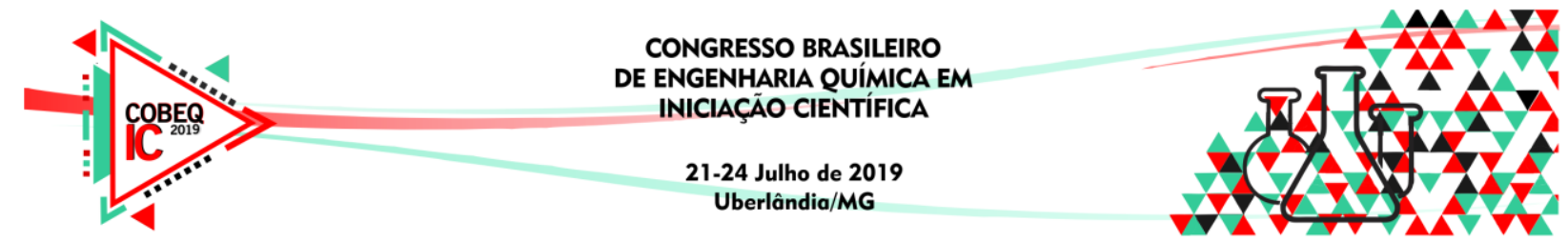

conversão de $40 \%$ de permeado, com condutividade relativamente baixa. Desse modo, a aplicação da NF se mostrou mais adequada para o tratamento do efluente têxtil, visto que produziu um permeado de qualidade em relação à sua condutividade, bem como obteve uma menor incrustação da membrana. Como a condutividade possui uma relação com a quantidade de sais dissolvidos totais, e este parâmetro é de suma importância para a avaliação de reúso de efluentes, pode-se dizer que para as análises feitas, o efluente tratado se mostrou apto para ser reutilizado na indústria nas etapas de lavagem, tingimento, branqueamento, limpeza de galpões, sanitários e equipamentos. Ademais, o tratamento proporcionou uma taxa de recuperação favorável, o que acarreta em vantagens à empresa, pois a mesma poderá operar o sistema com uma conversão de $40 \%$ do permeado.

\section{REFERENCIAS}

APHA, Standard Methods for the Examination of Water and Wastewater Part 4000 INORGANIC NONMETALLIC CONSTITUENTS Standard Methods for the Examination of Water and Wastewater. 1999.

BAFANA, A.; JAIN, M.; AGRAWAL, G.; CHAKRABARTI, T. Bacterial reduction in genotoxicity of direct red 28 dye. Chemosphere, V. 74, p. 1404-1406, 2009.

CHOLLOM, M. N., RATHILAL, S, PILLAY, V. L., ALFA, D. The applicability of nanofiltration for the treatment and reuse of textile reactive dye efluente. Water SA, v. 41, p. 398-405, 2015.

FIRMINO, P. I. M.; SILVA, M. E. R.; CERVANTES, F. J.; SANTOS, A. B. Colour removal of dyes from synthetic and real textil wastewater in one- and two-stage anaerobic systems. Bioresource Technology, v.101, p. 7773-7779, 2010.

KIM, J.-O.; TRAORE, M. K..; WARFIELD, C. The textile and apparel industry in developing countries. Textile Progress, V. 38:3, p. 1-64, 2006.

KORBAHTI, B. K.; TANYOLAÇ, A. Eletrochemical treatment of simulated textile wasterwater with industrial components and Levafix Blue CA reactive dye: Optimization through response surface methodology. Journal of Hazardous Materials, V. 151, p. 422-431, 2008.

KUNZ, A., PERALTA-ZAMORA, P, MORAES, S. G., DURÁN, N. Novas tendências no tratamento de efluentes têxteis. Química Nova, v. 25, p. 78-82, 2002.

MARCELINO, R. B. P. Aplicação de processos oxidativos avançados para o tratamento de efluente da produção de antibióticos. Belo Horizonte. 2014. Dissertação de Mestrado. Programa de Pósgraduação em Saneamento, Meio Ambiente e Recursos Hídricos - Universidade Federal de Minas Gerais, 2015.

RICCI, B. C. Avaliação do uso de processos de separação por membranas na remoção de metais, recuperação de ácido sulfúrico e na geração de água de reúso a partir de efluente de indústria de mineração de ouro. Belo Horizonte. 2015. Dissertação de Mestrado. Programa de Pósgraduação em Saneamento, Meio Ambiente e Recursos Hídricos - Universidade Federal de Minas Gerais, 2015. 